\title{
Ciência no feitiço: técnica vocal e o "formante do ator"
}

\author{
Suely Master
}

ator, durante um espetáculo teatral, precisa ao menos ser ouvido e entendido para que a sua fala possa afetar a platéia, despertando sensações, emoções, transportando-a para o mundo do imaginário. Falar é agir! É transmitir por meio do valor das palavras, das nuances da entonação, das pausas de um texto, as intenções e ações do personagem. Era o que Stanislavski, ${ }^{1}$ o grande diretor do Teatro de Arte de Moscou, falava para seus alunos em meados de 1897. Com ele, morre o ator de um papel só e nasce o ator que imita a vida. Com arte! E foi também neste momento de renovação de toda uma estética teatral vigente, que marcou a superação do romantismo e a busca de um realismo poético, que o virtuosismo vocal passou a não mais comover o espectador como o fazia antes! Aos poucos, a velha arte de declamar das escolas românticas francesas e italianas foi sendo substituída por uma fala mais "natural", mais "verdadeira"

No Brasil, no Rio de Janeiro do Séc. XIX, quando predominavam nos nossos palcos os atores portugueses e as constantes visitas de companhias estrangeiras, principalmente as francesas, João Caetano, ${ }^{2}$ com suas Lições Dramáticas, trouxe algum progresso ao introduzir noções sobre técnica vocal para o teatro. Antes dele, a declamação era uma espécie de cantiga monótona, como uma ladainha. Mas foi só em 1956, no Primeiro Congresso Brasileiro da Língua Falada no Teatro, que se recomendou o uso nos nossos palcos do português padrão do Rio de Janeiro (Nunes, 1976, p. 157). Consolidouse então uma emissão "impostada", com voz grave e exagerada, com o " $r$ " vibrante, estimu-

Suely Master é fonoaudióloga, professora do Instituto de Artes e do Programa de Pós-Graduação em Artes da Unesp.

1 Konstantin Sergueievitch Alekseiev, pseud. Stanislavski (1863 - 1938) foi diretor, ator e crítico teatral russo. Por volta de 1989 fundou com o autor e diretor Vladimir Nemirovitch-Danchenko,, o Teatro de Arte de Moscou. Assumiu a direção do Estúdio de Ópera de Bolshoi em 1918, onde desenvolveu seu método de interpretação. Sobre seu trabalho com os atores, destacamos três obras fundamentais: $A$ preparação do ator (1968), A criação de um papel (1972) e a Construção do personagem (1976).

2 João Caetano Santos (1808-1863) foi dramaturgo e ator brasileiro, nascido no Rio de Janeiro. Suas iniciativas como ator e ainda, na administração de companhias dramáticas, marcaram o início do teatro brasileiro enquanto atividade profissional. A primeira companhia de João Caetano assinalou seu rompimento com a tradição pois até então os artistas, a linguagem e os repertórios vinham de Portugal. O ator publicou dois livros: Reflexôes dramáticas (1837) e Liçôes dramáticas (1862). 
lada por renomados professores de voz para o teatro até meados da década de 90. A despeito de algumas felizes exceções (que, no entanto, insistem no uso poético de termos cunhados e consagrados pela ciência tais como "ressonância”, gerando bastante confusão) persiste nos dias atuais um padrão de "impostação vocal". Marcado por um conhecimento limitado da fisiologia vocal, e por um pseudo-aconselhamento técnico, o trabalho nesta linha tem como pretensão ampliar as possibilidades vocais do ator, mas, por não respeitar suas características psicofísicas, acaba tornando-o profundamente artificial e limitado na busca da expressividade. Por outro lado, ainda que restritos às universidades brasileiras, temos os mais atualizados estudos de técnicas vocais que se baseiam em novos conceitos da fisiologia e em conhecimentos provenientes de moderníssimos aparatos tecnológicos - os chamados "Laboratório de Voz". Dentre estes equipamentos que possibilitam ao ator acompanhar de maneira mais objetiva as múltiplas características da sua própria voz, destacamos os programas de análise acústica computadorizada, objeto deste artigo.

\section{Projeção enquanto qualidade de voz: análise subjetiva}

Para que se possa entender o uso da análise acústica no treinamento da voz do ator, faz-se necessário abordar o conceito de qualidade de voz tanto do ponto de vista da sua percepção quanto da acústica. Muitos são os adjetivos usados para qualificar a voz do ator: voz ressonante, voz sonora, vibrante, mas o mais comum é dizermos que a voz cênica precisa ser projetada. A projeção, fenômeno multifatorial no que se refere especificamente à voz humana, pode ser entendida como uma qualidade de voz, equivalente ao que antigamente se conceituava como timbre. Ao longo dos anos, a qualidade da voz veio sendo preferencialmente avaliada por meio da escuta que, apesar de ser soberana e imprescindível, apresenta um certo grau de subjetividade, pois implica em um julgamento tem como referência padrōes internos que variam de indivíduo para indivíduo. E assim, o que é projetado para um poderá não ser para o outro, o que acaba gerando uma certa discordância e dificuldade de se assumir um consenso em torno do uso desta ou daquela terminologia (Bele, 2006, p. 555).

\section{Análise acústica da qualidade vocal: avaliação objetiva}

Esta qualidade vocal também pode ser avaliada de maneira mais objetiva, por meio da análise acústica computadorizada, usando-se o espectro de som. Espectro sonoro é a distribuição, no dominio das freqüências, do conjunto de todas as ondas que formam um som. É composto da amplitude da freqüência fundamental e de cada um dos harmônicos ou parciais que soam junto à fundamental. O espectro de um som é o correlato acústico da qualidade da voz e pela maneira como a energia do som se distribui ao longo de cada freqüência (fundamental e harmônicos), podemos ter uma idéia da qualidade de uma voz. Um gráfico de espectro sonoro é composto de barras, cada uma delas representando a amplitude de uma das freqüências componentes do som analisado. Amplitude e freqüência significam a altura e a intensidade de som, terminologia que se refere à acústica. $\mathrm{Na}$ psicofísica que estuda a sensação subjetiva que o som causa, estes parâmetros são respectivamente denominados de pitch e loudness. Energia sonora ou energia acústica, por sua vez, é a quantidade de som produzida no momento em que o ar passa pelas pregas vocais, colocando-as em vibração. Este som viaja até os nossos ouvidos como ondas sonoras, que são vibrações no ar, e atinge nossos ouvidos. No ouvido interno, ele é transformado em sinais elétricos que então seguem pelos nervos até o cérebro, onde é finalmente percebido.

E o que determina a qualidade de uma voz? Tanto as contribuições que vem da fonte glótica, ou seja, do modo como as pregas vocais vi- 
bram e da sua estrutura anatômica, quanto do filtro, que são as caixas de ressonância. (aliás o termo ressonância vem sendo usado com muita liberdade poética e sem nenhuma relação com a fisiologia o que, cientificismo à parte mas não desconsiderado, também acaba gerando uma série de equívocos. É a voz que ressoa na perna, no braço...). Quando as pregas vocais vibram, produzem um som complexo que é composto por uma freqüência fundamental (f0) e um número infinito de harmônicos. Vozes ricas, de excelente qualidade, têm um grande número de harmônicos. Estes harmônicos, ao passar pelas cavidades que estão acima das pregas vocais - supralaringe, faringe, boca e nariz - também são conhecidas como caixas de ressonância, podem ou não ser amplificados. O que vai ou não ser amplificado ou a habilidade de transferir o som da laringe até os lábios, depende das freqüências naturais de ressonâncias deste trato vocal, chamadas de freqüências formantes. No que diz respeito à voz, os cincos primeiros formantes (F) são especialmente importantes para as características de um som. O primeiro, o segundo e o terceiro formantes, respectivamente F1, F2 e F3, estão relacionados mais com a qualidade de uma vogal e o quarto e o quinto formantes, F4 e F5, com a qualidade de uma voz, no caso, com a projeção.

A freqüência de um formante depende basicamente da forma tridimensional do trato vocal, região que se estende das pregas vocais até os lábios, e que é definida pela posição dos articuladores: lábios, mandíbula, língua, palato mole e a própria laringe. Nesta concepção, articulação e ressonância são processos intimamente ligados. Quando se move um articulador, mudam-se as freqüências formantes. As frequiências do F1, F2 e F3 são mais instáveis: o F1 é particularmente sensível às mudanças na abertura da mandíbula, o F2 está mais relacionado com o ponto de constrição da língua no palato e o F3, ao tamanho da cavidade definida pela língua e região dos dentes incisivos. A frequiência do F4, assim como todas as outras freqüências formantes dependem, em princípio, da extensão do trato vocal. Esta extensão pode ser modificada pela movimentação da laringe para cima e para baixo e dos lábios projetados ou retraídos. Com a diminuição do comprimento do trato vocal todas as freqüências formantes ficam mais agudas. Com o aumento desse comprimento, por exemplo, pelo abaixamento da laringe no pescoço, técnica vocal muito conhecida pelos cantores líricos, as freqüências formantes tornam-se mais graves. $\mathrm{E}$ as vozes entoam soam mais claras ou mais escuras. Mas se na presença deste ajuste motor houver ainda um aumento da faringe e as áreas funcionais da laringe e da faringe estabelecerem entre si uma proporção de 1:6, a laringe assim isolada do restante do trato vocal passa a atuar como um ressonador independente e ter a sua própria freqüência de ressonância. Essa configuração de trato vocal está também na gênese de um evento acústico diretamente ligado à percepção de projeção da voz em atores masculinos, o "formante do ator" (FA).

\section{0 "formante do ator" enquanto resultado do fenômeno de ressonância}

Enquanto fenômeno de ressonância, o "formante do ator" pode ser identificado nos espectros de som como um pico na região de 3.500 Hz. Resultado do agrupamento do quarto e do quinto formantes, sua amplitude varia entre $15 \mathrm{~dB}$ e $25 \mathrm{~dB}$, existindo ainda uma diferença de $10 \mathrm{~dB}$ entre o pico e os vales que o circundam. $\mathrm{Na}$ Figura abaixo podemos ver o "formante do ator" na região de 3000-4000 Hz.

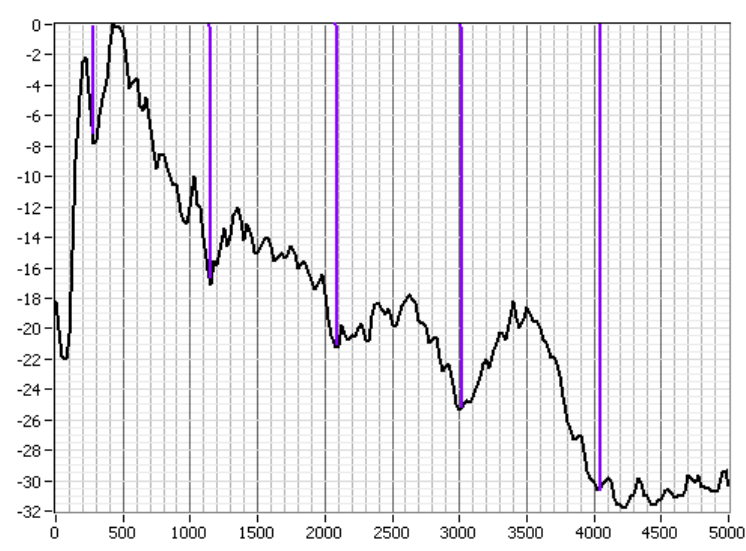




\section{0 espectro médio de longo termo e o "formante do ator"}

Dentre as várias possibilidades de análise espectrográfica, o espectro médio de longo termo (EMLT) é o método que estamos usando com relativo sucesso, para acompanhar a evolução do treino vocal dos nossos alunos e atores. Este espectro é resultado da somatória média de vários espectros simultâneos obtidos a partir de segmentos longos de fala como a fala espontânea, a leitura de um texto, o canto. Nele é possível identificarmos tanto a contribuição da fonte glótica (vibração das pregas vocais) quanto do filtro (caixas de ressonância) para a qualidade de uma voz Isso significa que podemos ter uma idéia da força que se faz em nível de pregas vocais para emitir a voz e se estamos ou não usando de maneira adequada as nossas caixas de ressonância.

Em linhas gerais, ao olharmos o EMLT procuramos, em primeiro lugar, ter uma indicação da inclinação da curva espectral (Master et al., 2006, p. 111). O declínio desta curva, mais ou menos acentuado, está relacionado à vibração das pregas vocais. Vozes de atores perceptivamente avaliadas como sendo projetadas, de ótima qualidade, fortes, apresentam grande concentração de energia acústica na região mais aguda do espectro (Leino, 1994, p. 206; Bele, 2006, p. 555). Em segundo lugar, mensuramos os picos que se formam no espectro e que correspondem às freqüências formantes - freqüências naturais de ressonância do trato vocal. Particularmente, a região que se estende entre 3000-4000 Hz, região do "formante do ator", é a que mais nos interessa por estar relacionada com a projeção vocal, com o brilho da voz e com vozes de boa qualidade (Leino, 1994, p. 206). Outros estudos realizados com atores masculinos de diferentes nacionalidades usando o EMLT, abordam a questão da existência de um "formante do ator" (Munro et al., 1996, p. 55; Bele, 2006, p. 555; Pinczower \& Oates, 2005. p. 440; Master et al., 2007).
Comparando as vozes de atores masculinos brasileiros com as vozes de não atores em intensidade habitual e forte, estudos com atores brasileiros mostraram que embora as vozes dos atores tenham sido percebidas como sendo mais fortes e mais projetadas e os espectros de som médios tivessem uma inclinação menos acentuada das suas curvas, o pico na regiāo do F4 não caracterizava, em princípio, um "formante do ator" levando em consideração a definição proposta por Leino. Nessa pesquisa foi possível concluir que esta menor inclinação da curva do espectro, significando um aumento de energia acústica na região dos harmônicos mais agudos, estaria relacionada com um aumento da força da musculatura envolvida no fechamento das pregas vocais durante a fonação, ou seja, especificamente este grupo de atores, não faz uso de ressonância enquanto estratégia de produção da voz cênica, revelando uma técnica vocal não tão eficiente, pois, apesar do bom resultado voz projetada - existe um grande esforço muscular envolvido neste processo (Master et al, 2007, in press).

\section{Treinamento vocal e o 'Formante do Ator'}

O "formante do ator" pode ser fortalecido por meio do treino de voz e dicção. Leino e Kärkkäinem (1995, p. 496) compararam espectros de alunos de teatro antes e depois do treinamento vocal e observaram uma inclinação menos acentuada da curva espectral - provavelmente devido ao aumento de energia nas freqüências mais agudas - além de um aumento significativo da freqüência central do formante do falante, em torno de $3500 \mathrm{~Hz}$. Laukkanen, Syrja, Laitala e Leino (2004, p. 66) treinaram a voz falada de um grupo de alunos de teatro finlandeses e notaram que após 2 meses de atividades, houve um aumento de 3 a $4 \mathrm{~dB}$ na regiāo do "formante do ator".

No Instituto de Artes da Unesp estamos desenvolvendo este trabalho com resultados 
bastante satisfatórios. Ao aluno é oferecida a possibilidade de treinar os seus exercícios enquanto visualiza sua voz, em tempo real, no espectro de som. A idéia, é trabalhar, entre outros parâmetros, o processo de ressonância ao fortalecer a energia acústica na região mais aguda do espectro, entre $2000-4000 \mathrm{~Hz}$, que é a região do "formante do ator".

Esta proposta de treinamento ocorre no terceiro ano letivo e é reforçada no quarto ano, depois que a voz já foi abordada nas disciplinas de jogos teatrais e improvisação no início do curso, resgatando seus aspectos lúdicos e criativos.

Em princípio, são apresentadas noções básicas de anatomofisiologia com enfoque nos processos de respiração, fonação e ressonância/ articulação, além de introdução à física acústica. Em seguida, partimos para o treinamento auditivo, quando voz é analisada em seus diferentes parâmetros: tipo de respiração, tom, modulação, intensidade, articulação, velocidade, ressonância. Estes parâmetros são posteriormente retomados em função do seu movimento expressivo reforçando a relação corpo-voz. Também faz parte do treinamento auditivo, criar referências sobre o que se espera atingir quando falamos de "projeção vocal" ou de qualidade de voz para o ator, respeitando sempre o potencial, as limitações e as características de cada um. A preservação da integração do corpo e da voz que é um dos pontos de partida do nosso trabalho, como foi mencionado anteriormente, tem o seu lugar antes do treino técnico. Os exercícios de bioenergética, as meditações dinâmicas e a prática do yoga são utilizadas com a finalidade de facilitar essa integração, tendo em vista a organicidade e a verdade das ações vocais.

Atualmente, no treino com análise acústica computadorizada, estamos usando o PRAAT, programa desenvolvido por Paul Boersma \& David Weenink (Praat: doing phonetics by computer [Computer program]) cujo download pode ser feito gratuitamente no site www.praat.org, e o Spectrogram Version 15, desenvolvido por Richard Horne. Um outro pro- grama, o Computerized Speech Lab (CSL), Model 4500, fabricado pela KayPENTAX, com alguns softwares mais específicos, deverá ser usado a partir do próximo ano no nosso "Laboratório de voz".

Os exercícios desenvolvidos têm como principais referências as propostas de Arthur Lessac (1976) e de Niilo Kuukka (Laukkanen et al., 2004, p. 76) mas Kristin Linklater (1976) também tem sido uma grande fonte de inspiração.

Assim, inicialmente gravamos a voz de cada aluno e fazemos o seu espectro médio de longo termo. Após seis meses de treino, um outro espectro será feito para comparação. Esta evolução deve ser revelada tanto pelo gráfico como pela percepção de projeção vocal.

Nesta figura extraída do GRAM, mostramos o espectro das vogais /a/ e /o/ depois de um aquecimento de 5 minutos de duração com vibração de lábios. Os harmônicos mais superiores podem ser claramente observados. Essa emissão é compatível com a percepção de projeção e sensação de facilidade na produção da voz.

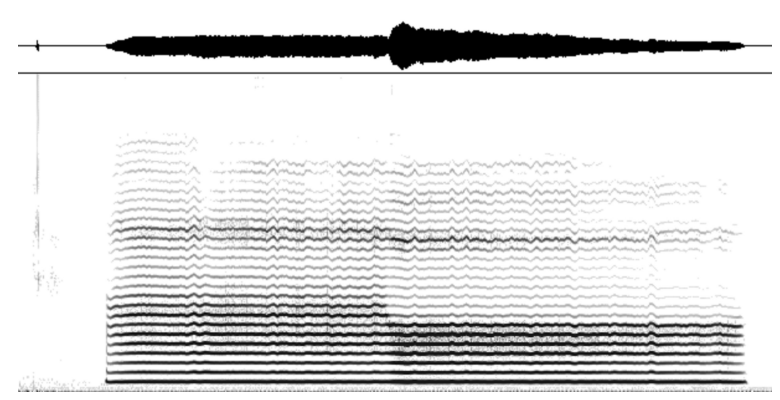

$\mathrm{Na}$ figura a seguir [próxima página], extraída do PRAAT, mostramos um trecho de leitura de texto onde podemos ver as modulações de fala, o tom, as pausas e a velocidade de fala que foram usadas. O aluno é então incentivado a explorar outras possibilidades tais como mudar o seu tom de voz, variar e ampliar a extensão de tons usados, deslocar as pausas, falar em diferentes velocidades. Assim, ao mesmo tempo, é possível ver e ouvir a voz, o que facilita muito o treino. 


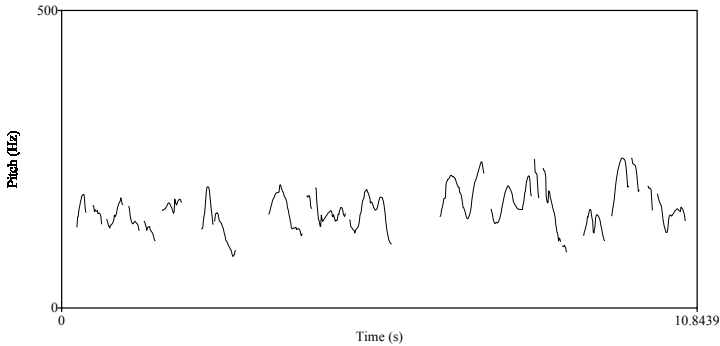

\section{Concluindo}

Diante desta nova realidade proposta pela análise acústica, destes novos achados que concretizam a questão da projeção vocal, o treinamento da voz do ator toma uma outra dimensão e pode ser desenvolvido de forma mais dirigida.

Falar com naturalidade não significa que se pode falar no palco como se fala na vida, pois a voz do ator em cena recebe, necessariamente, determinados ajustes para que o público presente ao espetáculo seja por ela afetado. Embora possam existir vozes especiais, naturalmente fortes e ressonantes, a voz cênica do ator pode ser desenvolvida por meio de um preparo técnico intenso. Com o objetivo de vencer a demanda vocal tendo em vista os diferentes tipos de palcos, dimensões de espaços teatrais, de acústicas mais ou menos eficientes, é preciso falar forte e ainda manter toda a carga emocional adequada, sem, entretanto, criar uma maneira artificial de se expressar. A expressividade, a plasticidade vocal, a possibilidade que o ator tem de encontrar "diferentes vozes" ao viver situaçōes cênicas, também encontra suporte em uma boa técnica. Este conhecimento técnico é básico para o ator, que tem na sua voz um instrumento de trabalho, e antecede a possibilidade de expressão artística.

Acreditamos, com base na nossa experiência acadêmica, que ao aprofundar a compreensão de suas posturas vocais a partir do mapeamento em imagens computadorizadas, os espectros de som, fica muito mais fácil a apreensão e o treinamento de todos os parâmetros vocais - tom, modulação do tom, intensidade, ressonância, pausas e pausas respiratórias, além de novos ajustes articulatórios, parâmetros estes que, em movimento, possibilitam a expressividade livre e criativa. Portanto, trata-se de desenvolver a voz cênica ou então, de "limpar" o ator de vícios e estereótipos de interpretação sustentados por trejeitos de caras e bocas, de modulações artificiais da voz e de técnicas de escolas ultrapassadas como a dos velhos diseurs franceses!

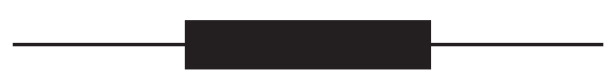

\section{Referências bibliográficas}

BELE, I. “The Speaker's Formant”. Journal of Voice, 20, p. 555-78, 2006.

CAETANO, J. Liçôes Dramáticas. Coleção Teatro. DF: MEC/Serv. Documentação, 1956.

LAUKKANEN, A. M.; SYRJA, T.; LAITALA, M. \& LEINO, T. "Effects of two-month vocal exercising with and without spectral biofeedback on student actor's voice. Logopedics, Phoniatrics". Vocology, 29, p. 66-76, 2004. 
LEINO, T. "Long term average spectrum study on speaking voice quality in male actors". In: FRIBERG, A.; IWARSSON, J.; JANSON, E. \& SUNDBERG, J. (Eds.). SMAC93. Proceedings of the Stockholm Music Acoustics Conference. Stockholm: Royal Swedish Academy of Music, 1994. p. 206-10.

LEINO, T \& KÄRKKÄINEN, P. "On the effects of vocal training on the speaking voice quality of male students actors”. In: ELENIUS, K. \& BRANDERUD, P. (Eds.). Proceedings of the XIII th International Congress of Phonetic Sciences. Stockholm: Department of Speech Communication and Music Acoustics, Royal Institute of Technology and the Department of Linguistics, Stockholm University, 1995, p. 496-9.

LESSAC, A. The Use and Training of the Human Voice: a bio-dynamic approach to vocal life. Mountain View: Mayfied Pub, 1976.

LINKLATER, K. Freeing the Natural Voice. New York: Drama, 1976

MASTER, S.; BIASE, N. D.; PEDROSA, V. \& CHIARI, B. M. "O espectro médio de longo termo na pesquisa e na clínica fonoaudiológica”. Pró-Fono Revista de Atualização Científica, 18, p. 111-20, 2006.

MASTER, S; BIASE, N. D.; CHIARI, B. M \& LAUKKANEN, A-M. "Acoustic and perceptual analysis of Brazilian male actors and nonactors' voices: long-term average spectrum and the 'actor's formant'”. Journal of Voice, corrected proof, 2007.

MUNRO, M.; LEINO, T. \& WISSING, D. "Lessac's “ $y$-buzz" as a pedagogical tool in the teaching of the projection of an actor's voice". Taalkunde Linguistics, 34, p. 25-36, 1996.

NUNES, L. Manual de Voz e Diç̧ão. Rio de Janeiro: Serviço Nacional de Teatro, 1976.

PINCZOWER, R. \& OATES, J. "Vocal projection in actors: the LTAS features that distinguish comfortable acting voice from voicing with maximal projection in males voice". Journal of Voice, 19, p. 440-53, 2005.

STANISLAVSKI, C. A construção da personagem. Rio de Janeiro: Civilização Brasileira, 1996. 